\title{
Notes from the Field: The impact of super typhoon Yolanda on the routine immunization program in the Philippines
}

\author{
Shane $A^{1 *}$ \\ ${ }^{1}$ Public Health Agency of Canada, Centre for Immunization and Respiratory Infectious Diseases, Ottawa, ON \\ * Corresponding author: Amanda.Shane@phac-aspc.gc.ca
}

On November 8, 2013, the most powerful typhoon ever recorded made landfall in Guiuan, Philippines. Before dissipating on November 11, the typhoon travelled west across 41 provinces. It is estimated that 16 million people were affected ( $17 \%$ of the total population), with 4.1 million displaced, 6,300 people reported dead and 1,061 missing $(1,2)$. The extensive damage to infrastructure, power and water supplies, as well as communications facilities was due to a combination of strong winds (recorded in excess of $300 \mathrm{~km} / \mathrm{h}$ in some areas) and the unexpected storm surges along some coastal areas, similar to what would be experienced as the result of a tsunami (1).

Through the Global Outbreak \& Alert Response Network (3), the World Health Organization (WHO) requested public health assistance from the Public Health Agency of Canada and I was one of the epidemiologists that provided support. Before I arrived, four of my colleagues from the Agency had already worked in the field for varying durations from November 2013 through to February 2014. They provided a range of guidance and support in a post-disaster response capacity in the areas of surveillance and outbreak response. When I arrived in late February 2014 (nearly four months post-disaster), the WHO Philippines had begun the shift from response to recovery, with a focus on longer term initiatives and programs.

Upon arrival, I was assigned as the WHO focal point for the Expanded Programme on Immunization in Region 8, the most heavily affected region. My primary objective was to conduct an assessment to determine how the typhoon had impacted routine immunization across the region. This was a continuation of the assessment initiated by a consultant from the U.S. Centers for Disease Control and Prevention who was in the region for a week in late February 2014. From February to April, 2014, 54 facilities in 35 municipalities were visited. The majority of facilities reported structural damage and loss of electricity due to the typhoon. As a result, a large proportion of facilities were required to interrupt their routine immunization activities. The median duration of interruption was eight weeks, but a subset of areas was without routine immunization for more than three months. However, at the time of the site visits, all facilities had managed to successfully resume their routine immunization activities.

Through this assessment, key criteria for successful immunization program recovery were identified. These included the importance of disaster-resilient cold chain equipment, well-established contingency plans for maintenance of the cold chain and clear processes for provision of immunization supplies (e.g. replacement records) and replacement vaccine stock in the event of a disaster. The results of the assessment will be used by the WHO and the Department of Health, Philippines, to resolve the challenges identified and to strengthen the routine immunization program.

My experience did include some challenges, specifically related to: understanding the complex public health system in the Philippines; developing meaningful relationships with key national/regional/provincial governmental and other non-governmental organization stakeholders in a very short time; and limitations resulting from logistics restrictions. However in spite of this, my overall impressions were very positive. I was impressed with the resiliency and professionalism of the Filipino health workers who I met through my travels across the region. Many of these people were directly affected by the typhoon and had lost family members, friends or colleagues in the disaster. Despite this, I witnessed a strong commitment to ensuring the children in their communities had access to the Expanded Programme on Immunization Vaccines. 


\section{References}

(1) Humanitarian Response Philippines. Multi-cluster/sector initial rapid assessment: Philippines typhoon Yolanda Haiyan.

https://philippines.humanitarianresponse.info/system/files/documents/files/20131129 MIRA Report Philippines Haiyan FINAL 1.pdf.

(2) National Disaster Risk Reduction and Management Council. NDRRMC update: Updates re: The effects of typhoon "Yolanda" (Haiyan).

http://www.ndrrmc.gov.ph/attachments/article/1177/Update\%20Effects\%20TY\%20YOLANDA\%2017\%20Apri \%202014.pdf.

(3) World Health Organization. Global Outbreak \& Alert Response Network (GOARN).

http://www.who.int/csr/outbreaknetwork/en/. 